\title{
Phenolic Profiles, Antioxidant Activity and Phenotypic Characterization of Lonicera caerulea L. Berries, Cultivated in Lithuania
}

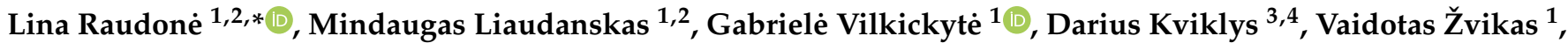 \\ Jonas Viškelis ${ }^{3}$ (i) and Pranas Viškelis ${ }^{3}$
}

check for updates

Citation: Raudonè, L.; Liaudanskas, M.; Vilkickytè, G.; Kviklys, D.; Žvikas, V.; Viškelis, J.; Viškelis, P. Phenolic Profiles, Antioxidant Activity and Phenotypic Characterization of Lonicera caerulea L. Berries, Cultivated in Lithuania. Antioxidants 2021, 10, 115. https://doi.org/10.3390/ antiox10010115

Received: 28 December 2020 Accepted: 11 January 2021 Published: 15 January 2021

Publisher's Note: MDPI stays neutral with regard to jurisdictional clai$\mathrm{ms}$ in published maps and institutional affiliations.

Copyright: (C) 2021 by the authors. Licensee MDPI, Basel, Switzerland. This article is an open access article distributed under the terms and conditions of the Creative Commons Attribution (CC BY) license (https:// creativecommons.org/licenses/by/ $4.0 /)$.
1 Laboratory of Biopharmaceutical Research, Institute of Pharmaceutical Technologies, Lithuanian University of Health Sciences, Sukileliu av. 13, LT-50162 Kaunas, Lithuania; mindaugas.liaudanskas@lsmuni.lt (M.L.); gabriele.vilkickyte@lsmu.lt (G.V.); vaidotas.zvikas@lsmuni.lt (V.Ž.)

2 Department of Pharmacognosy, Lithuanian University of Health Sciences, Sukileliu av. 13, LT-50162 Kaunas, Lithuania

3 Lithuanian Research Centre for Agriculture and Forestry, Institute of Horticulture, Kauno str. 30, Babtai, LT-54333 Kaunas, Lithuania; darius.kviklys@lammc.lt (D.K.); jonas.viskelis@lammc.lt (J.V.); pranas.viskelis@lammc.lt (P.V.)

4 Department of Horticulture, Norwegian Institute of Bioeconomy Research-NIBIO Ullensvang, Ullensvangvegen 1005, NO-5781 Lofthus, Norway

* Correspondence: lina.raudone@lsmuni.lt

\begin{abstract}
Lonicera caerulea L. is an early fruit-bearing plant that originates from harsh environments. Raw materials contain a body of different phenolic origin compounds that determine the multidirectional antioxidant and pharmacological activities. The aim of this study was to comprehensively evaluate the phenolic composition, antioxidant capacities, vegetative, pomological, and sensory properties and their interrelations of selected L. caerulea cultivars, namely 'Amphora', 'Wojtek', 'Iga', 'Leningradskij Velikan', 'Nimfa', 'Indigo Gem', 'Tundra', 'Tola', and fruit powders. Combined chromatographic systems were applied for the qualitative and quantitative profiling of 23 constituents belonging to the classes of anthocyanins, flavonols, flavones, proanthocyanidins, and phenolic acids. The determined markers of phytochemical profiles were cyanidin-3-glucoside, rutin, chlorogenic, and 3,5-dicaffeoylquinic acid. Anthocyanins and the predominant compound, cyanidin-3-glucoside, were the determinants of antioxidant activity. Cultivars 'Amphora', 'Indigo Gem', and 'Tundra' contained the greatest total amounts of identified phenolic compounds. Phenotypic characterization revealed the superiority of cultivars 'Wojtek' and 'Tundra' compared to other cultivars, although 'Wojtek' had low phenolic content and antioxidant activity and 'Tundra' got lower sensory evaluation scores. Coupling the results of phenotypic and phytochemical characterization, cultivar 'Tundra' could be suitable for commercial plantations.
\end{abstract}

Keywords: Lonicera caerulea L.; honeysuckle berry; phenolic profile; anthocyanins; antioxidant activity

\section{Introduction}

Lonicera L. genus (Caprifoliaceae Juss.) consists of about 200 species including ornamental, medicinal, and food plants [1]. One of the most economically important species is Lonicera caerulea L. (blue honeysuckle) bearing blue purple to dark blue fruits. The species is distributed in the Northern hemisphere, with main sites of origin in Russia, Canada, China, and Japan, growing in the continental climate zones Dwa, Dwb, Dwc, Dfb, Dfc climate regions [2-5]. The plant is highly resistant to various extreme environmental conditions and can successfully grow even in very harsh environments. An attractive trait is a fruitbearing time, depending on the growing region, it occurs in May or June, the plant being one of the earliest available Northern fruits in the season $[4,6,7]$. The fruits, commonly 
known as berries (multiple fruits botanically) have been traditionally used as food and longevity sources in traditional local medicines. The fruits have been historically used to treat heart, eye, and gastrointestinal diseases $[1,8]$. Scientific research determined the health-promoting and therapeutic properties indicating cardioprotective, microcirculation improving, anti-diabetic, antibacterial, UV-photoprotective, chemopreventive, chemotherapeutic, anti-inflammatory, hepatoprotective, neuroprotective, and antioxidant effects of L. caerulea extracts $[1,4,8]$. Oxidative stress is strongly interrelated with inflammation, cancer, and other chronic degenerative diseases. The multidirectional antioxidant activity could interact with various oxidative stress implicated mechanisms, modulate the status of the cells, and express anti-inflammatory, degenerative preventive, or therapeutic effects [9]. Pharmacological effects are mainly determined by the body of distinct chemical origin bioactive compounds, namely, ascorbic acid, phenolic compounds, iridoids, triterpene compounds, carotenoids, fatty acids, and others $[1-4,9,10]$.

L. caerulea fruits contain a significant amount of ascorbic acid with the amounts superior to other Northern fruits [2,11]. The phenolic fraction is constituted of hydroxycinnamic acids, anthocyanins, flavonols, flavones, flavan-3-ols. Their qualitative and quantitative profiles vary significantly, with the predominance of anthocyanins, flavonols, and caffeoylquinic acids $[1,3,4,7,8,10]$. Due to rich phytochemical composition blue honeysuckle fruits have been assigned to superfoods $[3,9]$.

The qualitative anthocyanin profile is specific and characteristic to $L$. caerulea fruits, consisting of cyanidin-3-glucoside as the predominant compound (up to $90 \%$ ) followed by cyanidin-3,5-diglucoside, peonidin-3-glucoside, and other minor anthocyanins [1]. The quantitative profiles vary significantly depending on horticultural cultivar, climatic and edaphic conditions of the growing area [2]. Auzanneau et al., 2018 determined that the growing year also affects the total amount of secondary metabolites [2]. Widespread species, growing in different climatic zones, possess differences in phytochemical composition within the same genotype [12]. Standardized growing conditions are in need to obtain chemically homogenous raw materials and are relevant for the sustainability of resources. The cultivated varieties occur from L. caerulea subspecies, the most common and easiest to grow being namely, 'Tundra', 'Borealis', 'Aurora', 'Indigo' series and 'Boreal' series. The research on cultivated blue honeysuckle is performed in Canada, Asia, and European countries and the cultivars differ in pomological characteristics, sensory properties, and phytochemical compositions $[2,7,9,13-16]$. The cultivars with determined phytochemical profiles and markers can be selected for standardized plantations [17]. Plantations have already been established in Russia and Japan, and the emerging research in other countries confirms the relevance. In Lithuania, the genetic research was performed on collection cultivars but no phytochemical profiling was performed up to date [18]. The evaluation of phenotypic traits, growing conditions, and coupling them to phytochemical profiles are essential for the production of the high-quality raw materials corresponding to the geo-authentic materials [12].

Blue honeysuckles contain small seeds that are imperceptible during consumption. Fruits can be easily freeze-dried, which ensures the retaining of color and bioactive compounds $[6,19]$. Freeze-dried powders are versatile with no waste technologies supporting products $[20,21]$. They can be easily incorporated in smart packaging indicating food spoilage due to $\mathrm{pH}$ changes and in functional food or other added-value products with notable antioxidant activity $[4,22]$.

The aim of our study was to comprehensively evaluate the phytochemical composition, antioxidant capacities, vegetative, pomological, and sensory properties and their interrelations of selected L. caerulea cultivars ('Amphora', 'Wojtek', 'Iga', Leningradskij Velikan', 'Nimfa', 'Indigo Gem', 'Tundra', 'Tola') fruit powders. The superior cultivars could be promoted for commercial crops in Dfb climatic regions with further functionalization of health-promoting products. 


\section{Materials and Methods}

\subsection{Plant Material}

Vegetative growth parameters, yield, and fruit quality of eight Lonicera caerulea cultivars originated from Canada, Poland and Russia were investigated at the Institute of Horticulture, Lithuanian Research Centre for Agriculture and Forestry (Table 1) (55 $4^{\prime} 55.67^{\prime \prime}$, $23^{\circ} 47^{\prime} 53.99^{\prime \prime}$ (World Geodetic System)). The plantation was established in 2016 on black woven mulch, planting distances were $3 \times 1 \mathrm{~m}$. A total of 10 plants of each cultivar were planted under a full randomized scheme.

Table 1. Cultivar origin and ripening time.

\begin{tabular}{ccc}
\hline Cultivar & Origin & Time of Ripening \\
\hline 'Amphora' & Canada & Early \\
'Wojtek' & Poland & Medium early \\
'Iga' & Poland & Medium early \\
'Leningradskij Velikan' & Russia & Medium early \\
'Nimfa' & Russia & Medium early \\
'Indigo Gem' & Canada & Medium late \\
'Tundra' & Canada & Medium late \\
'Tola' & Poland & Late \\
\hline
\end{tabular}

Vegetative growth was evaluated by measuring shrub height $(\mathrm{cm})$ and width $(\mathrm{cm})$. Shrub density was evaluated on the 5-point scale, where 1 -very sparse; 5 -very dense. Shrub health status was evaluated on the 5-point scale, where 1-dying; 5-excellent status. Annual yield $(\mathrm{kg})$ per individual shrub was recorded and accumulated yield $(\mathrm{kg})$ during 2018-2020 is presented as an average of ten shrubs. Berries were harvested when their color was uniform and berries easily separated from the stalk. Average berry weight $(\mathrm{g})$ was measured of the sample of 100 berries. The three-year average weight is presented. Berry shape was established according to descriptors. Fruit sensory evaluation was done by trained panelists in 2020. Average scores of 7 evaluations are presented.

\subsection{Preparation of L. caerulea Extracts}

Fruits were collected and immediately subjected to freeze-drying in a Zirbus lyophilizer (Zirbus Technology $\mathrm{GmbH}$, Bad Grund, Germany) at 0.01 mbar pressure and $-85^{\circ} \mathrm{C}$ condenser temperature. The dried fruits were milled to powder and kept in a sealed container in a dark dry place. About $1 \mathrm{~g}$ (precise weight) of freeze-dried L. caerulea powder was weighted in a dark glass vial, with $10 \mathrm{~mL}$ of $80 \%(v / v)$ ethanol acidified with $2 \%$ hydrochloric acid. The extraction process continued for $40 \mathrm{~min}$ at $80 \mathrm{~Hz}$ and $904 \mathrm{~W}$, in an ultrasonic bath (Elmasonic P, Singen, Germany). The extracts were filtered through $0.22 \mu \mathrm{m}$ pore size membrane filters (Carl Roth $\mathrm{GmbH}$, Karlsruhe, Germany) and transferred to the dark glass vials.

\subsection{Chemicals}

All the solvents, reagents, and standards used were of analytical grade and met all the set quality requirements. The following substances were used in the study: ethanol $96 \%$ $(v / v)$ (AB Vilniaus degtine, Vilnius, Lithuania), ABTS (2,2'-azino-bis(3-ethylbenzothiazoline6-sulfonic acid), Trolox (6-hydroxy-2,5,7,8-tetramethyl-chroman-2-carboxylic acid), potassium persulfate, acetic acid, ammonia acetate, neocuproine (Scharlau, Sentmenat, Spain), TPTZ (2,4,6-Tris(2-pyridyl)-s-triazine) (Carl Roth, Karlsruhe, Germany), iron (III) chloride hexahydrate (Vaseline-Fabrik Rhenania, Bonn, Germany), acetonitrile, cyanidin3-glucoside chloride, cyanidin-3,5-diglucoside chloride, cyanidin-3-rutinoside chloride, peonidin-3-glucoside chloride, cyanidin chloride, cyanidin-3-galactoside chloride, peonidin chloride, rutin, isoquercitrin, quercitrin, quercetin, isorhamnetin, apigenin, luteolin-7-Oglucoside, procyanidin $\mathrm{B} 1$, chlorogenic acid, caffeic acid, p-coumaric acid, ferulic acid, DMCA (4-(dimethylamino)-cinnamaldehyde), hydrochloric acid, (-)-epicatechin, sodium 
acetate trihydrate, copper (II) chloride dihydrate, formic acid (Sigma-Aldrich, Steinheim, Germany). During the study, we used purified de-ionized water prepared with the Milli-Q ${ }^{\circledR}$ (Millipore, Bedford, MA, USA) water purification system.

\subsection{Spectrophotometric Assays}

\subsubsection{Determination of Total Proanthocyanidins}

The procedure for the determination of total proanthocyanidins used in the present study is described in Heil et al., 2002 [23]. Briefly, $10 \mu \mathrm{L}$ of L. caerulea fruit extract was mixed with $3 \mathrm{~mL}$ of $0.1 \%$ DMCA reagent dissolved in acidified ethanol (9 parts $96.3 \%$ ethanol and 1 part $36 \%$ hydrochloric acid). The reference solution was DMCA solution in acidified ethanol. After $5 \mathrm{~min}$, the absorption of the test solution was measured with an M550 UV / $V$ is spectrophotometer (Spectronic CamSpec, Garforth, UK) at a wavelength of $640 \mathrm{~nm}$. The total amount of proanthocyanidins was calculated from a (-)-epicatechin calibration curve and expressed as $\mathrm{mg} / \mathrm{g}(-)$-epicatechin equivalent (EE) per one gram of dry weight (DW).

\subsubsection{Antioxidant Activity Assays}

The ABTS assay was performed as described by Re et al., 1999 with some modifications [24]. Briefly, $3 \mathrm{~mL}$ of diluted ABTS radical cation solutions, produced by reacting $7 \mathrm{mM}$ ABTS aqueous solution with $2.45 \mathrm{mM}$ potassium persulfate and allowing the mixture to stand for $16 \mathrm{~h}$ in dark, were mixed with $20 \mu \mathrm{L}$ of extracts. The decrease in absorbance was recorded at $734 \mathrm{~nm}$ after $1 \mathrm{~h}$ of incubation.

The ferric reducing activity (FRAP) was determined according to the method of Benzie and Strain (1996) [25]. During the evaluation, $3 \mathrm{~mL}$ of freshly prepared solutions of FRAP reagent, consisting of $300 \mathrm{mM}$ acetate buffer, $10 \mathrm{mM}$ TPTZ in $40 \mathrm{mM} \mathrm{HCl}$, and $20 \mathrm{mM}$ iron (III) chloride in a final ratio of 10:1:1 $(v / v / v)$ were mixed with $20 \mu \mathrm{L}$ of extracts, following by incubation for $1 \mathrm{~h}$ and absorbance recording at $593 \mathrm{~nm}$.

The CuPRAC (cupric-reducing antioxidant capacity) assay was performed as described by Apak et al., 2007 [26]. In this assay, $3 \mathrm{~mL}$ of solutions of CuPRAC, consisting of $0.01 \mathrm{M}$ copper (II) chloride, $0.001 \mathrm{M}$ ammonium acetate buffer solution, and $0.0075 \mathrm{M}$ neocuproine in a final ratio of 1:1:1 $(v / v / v)$, were mixed with $20 \mathrm{~mL}$ of extracts, and the absorbance was measured at $450 \mathrm{~nm}$.

All antioxidant activity measurements and calculations were performed using Trolox calibration curves and were expressed as $\mu \mathrm{mol}$ of the Trolox equivalent (TE) per one gram of dry weight, according to our previous research [27].

\subsection{Chromatographic Assays}

Quantification and profiling of phenolic acids, proanthocyanidins, flavonoids were performed using the validated high performance liquid chromatography (HPLC) method by Liaudanskas et al., 2014 [28] on a Waters 2695 chromatography system with a Waters 2998 PDA (photodiode array) detector (Waters, Milford, MA, USA). The chromatographic separation was performed on a YMC-Pack ODS-A C18 $(250 \times 4.6 \mathrm{~mm} ; 5 \mu \mathrm{m})$ column equipped with a YMC-Triart C18 $(10 \times 3.0 \mathrm{~mm} ; 5 \mu \mathrm{m})$ precolumn (YMC Europe $\mathrm{GmbH}$, Dinslaken, Germany) at a constant temperature of $25{ }^{\circ} \mathrm{C}$. The flow rate was $1 \mathrm{~mL} / \mathrm{min}$, injection volume-10 $\mu \mathrm{L}$. Gradient elution $(2 \%(v / v)$ acetic acid $(\mathrm{A})$ and $100 \%(v / v)$ acetonitrile (B)): 0-30 min, 3-15\% B; 30-45 min, 15-25\% B; 45-50 min, 25-50\% B; and 50-55 min, $50-95 \%$ B. The peaks were identified comparing retention times, spectral characteristics of analytes, and reference compounds.

The UPLC-ESI-MS/MS (ultra performance liquid chromatography with electrospray ionisation mass spectrometry) was performed using a previously described method by Gonzalez-Burgos et al., 2018 [29] using Waters ACQUITY UPLC ${ }^{\circledR}$ H-Class (Waters, Milford, MA, USA) with a tandem quadrupole mass detector Xevo TQD (Waters, Milford, MA, USA), YMC Triart C18 $(100 \times 2.0 \mathrm{~mm} ; 1.9 \mu \mathrm{m})$ column ("YMC", Kyoto, Japan). Gradient elution (0.1\%formic acid (A) and acetonitrile (B), flow rate $0.5 \mathrm{~mL} / \mathrm{min}$ ):A: initially $95 \%-1 \mathrm{~min}$; 
to $70 \%-4 \mathrm{~min} ; 50 \%-7 \mathrm{~min} ; 95 \%$ - over $2 \mathrm{~min}$. Collision energy and cone voltage were optimized for each compound separately. Retention times, compound molecular mass, and mass fragmentation were compared to literary data and reference compounds.

The variability in the qualitative and quantitative content of anthocyanins was evaluated by the validated method described by Vilkickyte et al. 2021 [30]. Chromatographic separation was performed with Waters ACQUITY Ultra-High-Performance LC system (Water, Milford, MA, USA) equipped with a photodiode array detector and an ACE Super C18 $(100 \times 2.1 \mathrm{~mm}, 1.7 \mu \mathrm{m})$ column $(\mathrm{ACT}$, Aberdeen, UK). The gradient elution system consisted of $10 \%(v / v)$ formic acid in water $(\mathrm{A})$ and $100 \%(v / v)$ acetonitrile $(\mathrm{B})$, and separation was achieved using the following gradient: 0-2 min, 5-9\% B; 2-7 min, 9-12\% B; 7-9 $\mathrm{min}, 12-25 \% \mathrm{~B}$; 9-10 $\mathrm{min}, 25-80 \% \mathrm{~B} ; 10-10.5 \mathrm{~min}, 80 \% \mathrm{~B} ; 10.5-11 \mathrm{~min}, 80-5 \% \mathrm{~B}$; and 11.0-12.0 $\mathrm{min}, 5 \% \mathrm{~B}$ with flow rate $0.5 \mathrm{~mL} / \mathrm{min}$. The column was operated at a constant temperature of $30{ }^{\circ} \mathrm{C}$ and the injection volume was $1 \mu \mathrm{L}$. All anthocyanins were identified and quantified at $520 \mathrm{~nm}$ wavelength.

\subsection{Statistical Analysis}

Statistical analysis was performed using IBM SPSS 24.0 (SPSS Inc., Chicago, IL, USA) and Microsoft Office Excel 2017 (Microsoft, Redmond, WA, USA). All measurements were performed in triplicate, and results were expressed as mean \pm standard deviation (SD). The one-way analysis of variance was performed, and post-hoc Tukey HSD multiple comparison test was used to identify significant differences at $p \leq 0.05$. Radical scavenging and reducing activities were expressed as Trolox equivalent antioxidant activity as mean \pm SD. Principal component analysis (PCA) was performed considering factors with eigenvalues higher than 1. Regression analysis was performed for the calibration curves of concentration-response. Correlations were evaluated using the Pearson correlation coefficient.

\section{Results and Discussion}

\subsection{Evaluation of the L. caerulea Cultivars}

The blue honeysuckle shrubs still did not reach their final size in the 5th year after planting (Table 2). Shrub height and width varied among cultivars from 87 up to $120 \mathrm{~cm}$, and from 90 up to $110 \mathrm{~cm}$, respectively. Though there were significant differences between cultivars both for shrub height and width, some more years are needed to draw final conclusions. The two cultivars 'Amphora' and 'Leningradskij Velikan' were distinguished by very dense shrubs; this is a negative character that bears difficulties during the berry harvest. Other tested cultivars did not differ significantly in shrub density. The two Polish cultivars, 'Iga' and 'Tola', were the same as the Canadian cultivar 'Tundra'; in their 5th growing season, they had very healthy shrubs without any visual decline symptoms. 'Leningradskij Velikan' had the worst health status and the main negative symptoms were stunted new growth and leaf discoloration.

Table 2. Shrub parameters and health status of blue honeysuckle cultivars, 2020.

\begin{tabular}{ccccc}
\hline Cultivar & $\begin{array}{c}\text { Shrub Height, } \\
\mathbf{c m}\end{array}$ & $\begin{array}{c}\text { Shrub Width, } \\
\mathbf{c m}\end{array}$ & $\begin{array}{c}\text { Shrub Density * } \\
\text { (1-5 Scale) }\end{array}$ & $\begin{array}{c}\text { Health } \\
\text { Status }\end{array}$ \\
\hline 'Wojtek' & $120 \mathrm{a}$ & $100 \mathrm{~b}$ & $4.3 \mathrm{~b}$ & $4.6 \mathrm{~b}$ \\
'Indigo Gem' & $95 \mathrm{bc}$ & $90 \mathrm{~b}$ & $4.1 \mathrm{~b}$ & $4.0 \mathrm{~cd}$ \\
'Iga' & $120 \mathrm{a}$ & $100 \mathrm{~b}$ & $4.0 \mathrm{~b}$ & $5.0 \mathrm{a}$ \\
'Leningradskij Velikan' & $100 \mathrm{bc}$ & $110 \mathrm{ab}$ & $5.0 \mathrm{a}$ & $3.7 \mathrm{~d}$ \\
'Nimfa' & $107 \mathrm{ab}$ & $95 \mathrm{~b}$ & $4.0 \mathrm{~b}$ & $4.5 \mathrm{bc}$ \\
'Amphora' & $105 \mathrm{ab}$ & $110 \mathrm{ab}$ & $5.0 \mathrm{a}$ & $4.2 \mathrm{c}$ \\
'Tola' & $100 \mathrm{bc}$ & $110 \mathrm{ab}$ & $4.1 \mathrm{~b}$ & $4.9 \mathrm{ab}$ \\
'Tundra' & $87 \mathrm{c}$ & $128 \mathrm{a}$ & $4.3 \mathrm{~b}$ & $5.0 \mathrm{a}$ \\
\hline
\end{tabular}

* 1-very sparse; 2-sparse; 3-medium dense; 4-dense; 5-very dense; Different letters represent statistically significant differences $(p<0.05)$ between values within the same column. 
The highest cumulative yield was obtained of cultivar. 'Tundra' (Table 3). Cultivar 'Wojtek' also was very productive and did not differ significantly from cultivar 'Tundra'. A total of five $\mathrm{kg}$ of berries harvested during three years, from 3-5 year old shrubs, were higher than the yield reported from the trials in Poland, where 3-4 years old cultivar 'Wojtek' gave around $1 \mathrm{~kg}$ yield [31], though other authors claim that $2 \mathrm{~kg}$ of berries from a shrub is an average yield for 5-6 year old shrubs [32,33]. In our trial, berries were harvested in one pick though there are recommendations to harvest in 3-4 times, or even up to 7 times, to prevent loss of overripe berries [34]. To consider that conditions cumulative yields in our trial could be increased by 10-15\%. Cultivar 'Amphora' was the lowest yielding cultivar (1.8 kg during three years), and only cultivar 'Nimfa' did not differ significantly from it.

Table 3. Cumulative yield and fruit characteristics of honeysuckle cultivars, 2018-2020.

\begin{tabular}{cccc}
\hline Cultivar & $\begin{array}{c}\text { Cumulative Yield, } \\
\text { kg/Shrub }\end{array}$ & $\begin{array}{c}\text { Average Berry } \\
\text { Weight, }\end{array}$ & Berry Shape \\
\hline 'Wojtek' & $4.84 \mathrm{ab}$ & $1.15 \mathrm{a}$ & oval \\
'Indigo Gem' & $3.08 \mathrm{~cd}$ & $0.96 \mathrm{~b}$ & oval prolonged \\
'Iga' & $4.34 \mathrm{~b}$ & $1.19 \mathrm{a}$ & oval \\
'Leningradskij Velikan' & $3.22 \mathrm{c}$ & $1.05 \mathrm{ab}$ & prolonged \\
'Nimfa' & $2.37 \mathrm{de}$ & $0.95 \mathrm{~b}$ & prolonged \\
'Amphora' & $1.78 \mathrm{e}$ & $0.95 \mathrm{~b}$ & prolonged \\
'Tola' & $4.23 \mathrm{~b}$ & $1.02 \mathrm{ab}$ & oval \\
'Tundra' & $5.21 \mathrm{a}$ & $0.98 \mathrm{~b}$ & oval rounded \\
\hline Different letters represent statistically significant differences $(p<0.05)$ between values within the same column.
\end{tabular}

Average berry weight varied from 0.95 up to $1.19 \mathrm{~g}$ between cultivars (Table 2). Cultivars 'Iga' and 'Wojtek' had significantly larger fruits than most other cultivars tested. Such fruit size obtained in our trial is comparable to the results of some Polish and Slovenian trials $[16,35]$.

Szot and Lipa (2013) reported a significant increase in average berry weight after the shrub pruning [36], but usually pruning starts from the 6th-8th year after planting of blue honeysuckle plantations, and our plants did not reach that age yet.

Sensory evaluation revealed significant differences between cultivars in berry appearance, flavor, and taste character (Table 4). The most attractive were berries of 'Amphora', 'Wojtek' and 'Tola'. Berries of 'Iga' and 'Tundra' were evaluated to have a significantly lower total score. On the other hand, 'Leningradskij Velikan' berries had the best flavor score, possibly related to higher dominance of sweetness. The flavor score of the most attractive 'Amphora' and 'Tola' berries was the lowest, the same as 'Iga', which lead to lower overall evaluation. It is interesting that the taste character of all these cultivars was evaluated as sour or acid. Combining berry appearance and flavor, 'Leningradskij Velikan' had the highest ratings, whereas 'Indigo Gem', 'Nimfa' and 'Wojtek' did not differ significantly.

Table 4. Sensory characteristics of honeysuckle cultivars, 2018-2020.

\begin{tabular}{ccccc}
\hline Cultivar & Appearance & Flavor & Total Score & Taste Character \\
\hline 'Wojtek' & $4.64 \mathrm{ab}$ & $4.23 \mathrm{bc}$ & $4.38 \mathrm{abc}$ & sour sweet \\
'Indigo Gem' & $4.53 \mathrm{~b}$ & $4.59 \mathrm{ab}$ & $4.55 \mathrm{ab}$ & tangy \\
'Iga' & $4.45 \mathrm{bc}$ & $4.02 \mathrm{c}$ & $4.15 \mathrm{de}$ & sour sweet \\
'Leningradskij Velikan' & $4.01 \mathrm{~d}$ & $4.93 \mathrm{a}$ & $4.61 \mathrm{a}$ & sweet \\
'Nimfa' & $4.29 \mathrm{c}$ & $4.53 \mathrm{ab}$ & $4.45 \mathrm{abc}$ & sweet tangy \\
'Amphora' & $4.69 \mathrm{a}$ & $3.89 \mathrm{c}$ & $4.32 \mathrm{bcde}$ & acid \\
'Tola' & $4.62 \mathrm{ab}$ & $3.86 \mathrm{c}$ & $4.28 \mathrm{cde}$ & acid tangy \\
'Tundra' & $4.02 \mathrm{~d}$ & $4.21 \mathrm{bc}$ & $4.08 \mathrm{e}$ & sweet tangy \\
\hline
\end{tabular}

Different letters represent statistically significant differences $(p<0.05)$ between values within the same column. 


\subsection{Phenolic Profiles of Fruits of Selected L. caerulea Cultivars}

Phytochemical profiles are determined by genetic origin, harvesting, and processing techniques of the plant materials and the environmental growing conditions. Environmental conditions are one of the main detrimental factors affecting the qualitative and quantitative compositions of plant materials. Central Europe is ascribed to the region of favorable growing conditions for L. caerulea species, as well as Canada and Northern countries of origin [2,9]. The HPLC-PDA and UPLC-PDA assays enabled profiling and quantification of anthocyanins, flavones, flavonols, and hydroxycinnamic acid contents in selected cultivars (Figure 1). Anthocyanins were the prevailing compounds and constituted from 38 up to $91 \%$ of total identified compounds, flavonoid fraction comprised from 3 up to $36 \%$, and phenolic acids- $3-42 \%$.

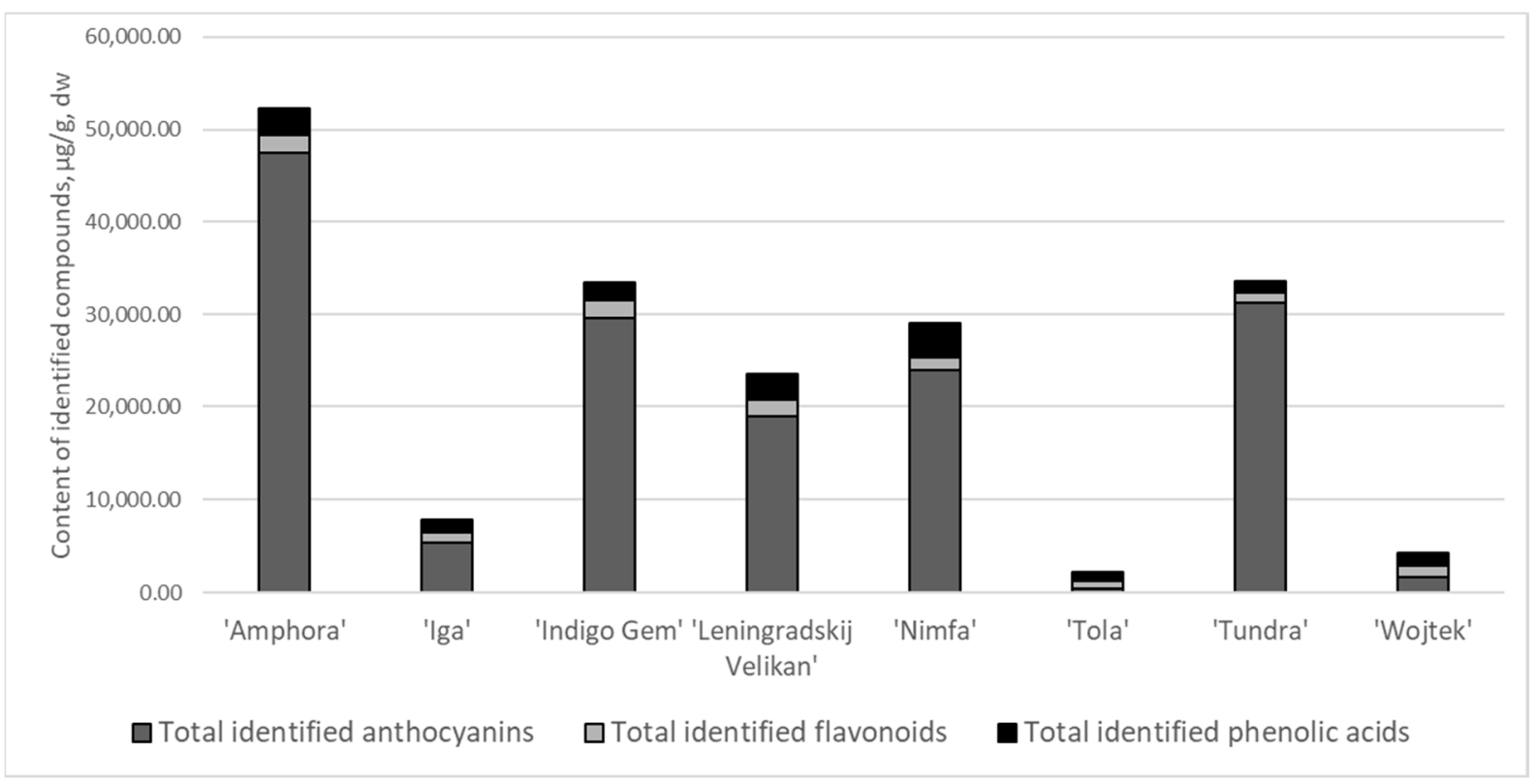

Figure 1. Content of total identified compound groups ( $\mu \mathrm{g} / \mathrm{g} \mathrm{DW}$ ) in L. caerulea fruits of different cultivars (flavonols, flavones and proanthocyanidns coupled to flavonoids).

The total amounts of identified anthocyanins varied significantly within the cultivars (Table 5). The greatest average amounts were determined in 'Amphora' ( 48 mg/g), 'Indigo Gem', 'Nimfa', 'Tundra', 'Leningradskij Velikan' ranging 19 to $31 \mathrm{mg} / \mathrm{g}$, and the lowest amounts were determined for 'Tola', 'Wojtek' and 'Iga' $-0.46,1.63$ and $5.39 \mathrm{mg} / \mathrm{g}$, respectively $(p<0.05)$. 
Table 5. Contents of individual phenolic compounds $(\mu \mathrm{g} / \mathrm{g}, \mathrm{DW})$ in cultivars of L. caerulea fruits.

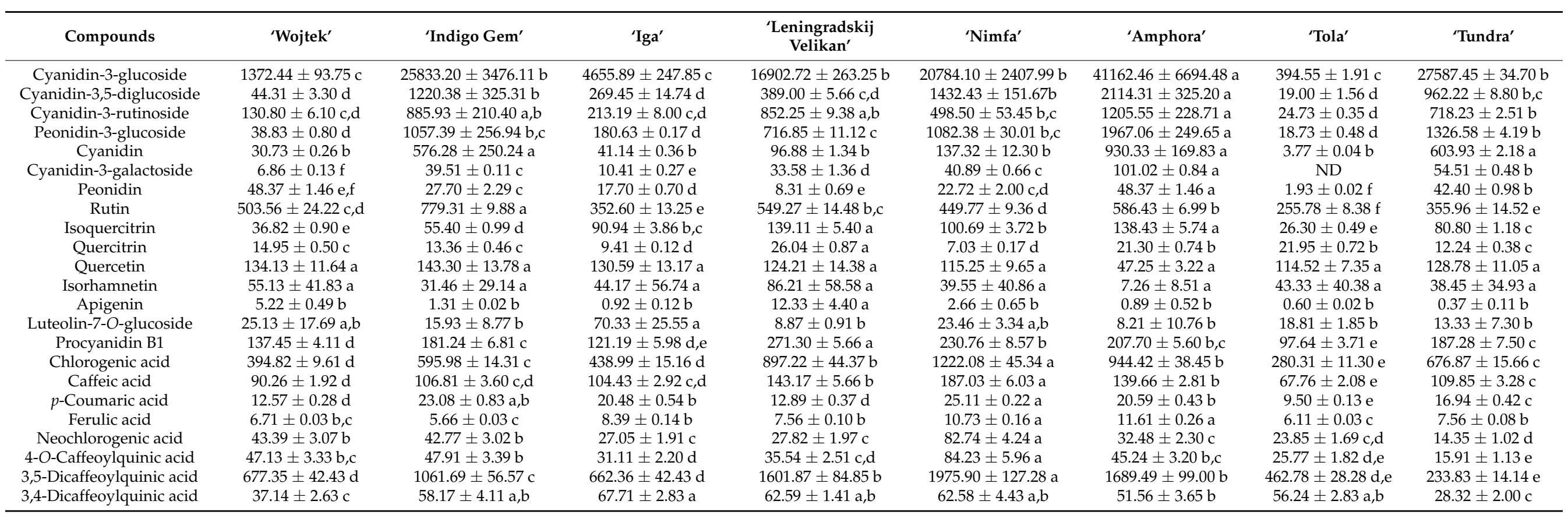

Different letters represent statistically significant differences $(p<0.05)$ between identified phenolic compounds within the same column; ND—not detected. 
The anthocyanin profile was predominated by the cyanidin-3-glucoside that accounted from 84 to $89 \%$ of total anthocyanins in cultivars 'Wojtek' and 'Leningradskij Velikan', respectively. The quantitative profiles of cyanidin-3,5-diglucoside, cyanidin-3-rutinoside, and peonidin-3-glucoside were cultivar specific, reaching up to 6,8 , and $4.5 \%$ of the total identified anthocyanins. The minor anthocyanins were up to $2 \%$. The total content of the identified anthocyanins negatively correlated with the average fruit weight $(R=-0.623$; $p<0.05)$. The profile of anthocyanins generally occurs in the following manner: cyanidin3-glucoside $>$ cyanidin-3,5-diglucoside $>$ cyanidin-3-rutinoside $>$ peonidin-3-glucoside $>$ pelargonidin-3-glucoside in L. caerulea genotypes [3,4,6,7,13]. Although certain authors indicate the presence of malvidin-3-glucoside, peonidin-3,5-diglucoside, pelargonidin-3glucoside, cyanidin-3-gentiobioside, and acetylated derivatives $[6,13,15]$. The key marker of anthocyanin profile of L. caerulea fruits is cyanidin-3-glucoside accounting for $70-90 \%$ of total amounts $[2-4,6,8,13,14]$. The average contribution of cyanidin-3-glucoside in our tested cultivars were $86 \%$, whereas the amounts of other identified anthocyanin derivatives were cultivar variant. The amounts of cyanidin-3-rutinoside tend to prevail after the cyanidin-3,5diglucoside [6,37], but our results show, that only cultivars 'Leningradskij Velikan', 'Wojtek' and 'Tola' confirm this trend. Caprioli et al., 2016 determined cyanidin-3,5-diglucoside as the second prevailing compound in the spontaneously growing L. caerulea var. kamtschatica samples from Russia [3]. Khattab et al., 2017 determined the predominance of cyanidin3-glucoside, peonidin-3-glucoside, and cyanidin-3,5-diglucoside in the profiles of Canadian cultivars 'Tundra' and 'Indigo Gem' [13]. Our results are in agreement confirming the second predominant compound peonidin-3-glucoside in 'Tundra' and cyanidin-3,5diglucoside in 'Indigo Gem' samples. On the other hand, peonidin-3,5-dihexoside was the second prevailing compound, followed by peonidin-3-glucoside in 'Tundra' samples, cultivated in Slovenia [11]. The quantitative levels tend to be low temperature and solar radiation dependent [6,9]. Growing conditions affect the total amounts of anthocyanins in cultivars [2,3]. Cyanidin-3-glucoside as the prevailing compound in the phenolic fraction, determine most of the pharmacological effects of $L$. caerulea extracts [8,38,39].

Rutin was the phytochemical marker of the flavonoids ranging from $255.78 \pm 8.38 \mu \mathrm{g} / \mathrm{g}$ in 'Tola' up to $779.31 \pm 9.88 \mu \mathrm{g} / \mathrm{g}$ in 'Indigo Gem' cultivar. The other quantified flavonoid derivatives were isoquercitrin, quercitrin, quercetin, isorhamnetin, luteolin-7-glucoside, and apigenin, showing significant quantitative variation between tested cultivars. The flavonoid profiles of L. caerulea consist of (+)-catechin, (-)-epicatechin, quercetin, isorhamnetin, kaempferol, apigenin, and glycosides and aglycones of luteolin [6,7,11]. Rutin is the predominant compound in the flavonoid fraction and can be regarded as the phytochemical marker. These results are in agreement with various studies regarding the chemical variation of flavonoids [7,11,13,37]. In our study, Russian cultivars contained the greatest amounts of flavonoids in the following order 'Nympha' > 'Amphora' > 'Leningradskij Velikan'. Gawronski et al., 2020 determined 'Aurora' with the highest amounts of flavonoids from the 30 tested L. caerulea cultivars [17]. Great variation in total contents of flavonoids was determined by various authors for the 'Indigo Gem', 'Leningradskij Velikan', 'Nimfa' cultivars due to different environmental conditions and growing techniques [17]. Anthocyanins and flavonoids are mainly located in skin tissues [6], therefore whole fruits or pomace materials could be selected for obtaining fruit powders for further functionalization [10].

The complex of hydroxycinnamic acids consisted of chlorogenic, caffeic, 4-O-caffeoylquinic, dicaffeoylquinic acids, p-coumaric, and ferulic acid. 3,5-dicaffeoylquinic acid prevailed in all tested cultivars (462.78-1975.90 $\mu \mathrm{g} / \mathrm{g})$, except 'Tundra' with the predominance of chlorogenic acid $(676.87 \pm 15.66 \mu \mathrm{g} / \mathrm{g})$. Hydroxycinnamic acids are important precursors of flavor and they are highly abundant and characteristic in fruits of different genera [1,11,40]. Chlorogenic acid and 3,5-dicaffeoylquinic acid are principal hydroxycinnamic acids in Lonicera fruits $[3,41]$. The complex can also variably contain ferulic, caffeic, p-coumaric, neochlorogenic, and other caffeoylquinic derivatives $[1,6,10]$. Kucharska et al., 2017 and Ozmianski et al., 2016 determined three monocaffeoylquinic and three dicaf- 
feoylquinic acids in L. caerulea fruits [7,10]. Liu et al., 2020 determined that chlorogenic acid together with cyanidin-3-glucoside and (+)-catechin inhibit $\alpha$-amylase activity and gain perspective as a hypoglycemic functional ingredient [41]. Another group of compounds possessing antihyperglycemic effects are proanthocyanidins [42].

Significantly, the greatest total amount of proanthocyanidins, determined by spectrophotometric DMCA method, were determined in samples of cultivars 'Amphora' and 'Leningradskij Velikan' (2.16 $\pm 0.03 \mathrm{mg} / \mathrm{g}$ and $2.13 \pm 0.01 \mathrm{mg} / \mathrm{g}$, respectively) (Table 7). The amounts of procyanidin B1, determined by HPLC-PDA method, were well correlated with the total amounts of proanthocyanidins $(R=0.886 ; p<0.05)$ and were highlighted in 'Amphora' and 'Leningradskij Velikan', while 'Tola' and 'Wojtek' contained the lowest amounts (Table 4). A much higher total of proanthocyanidins levels, compared to detected procyanidin $\mathrm{B} 1$ amounts, indicate that there are much more unidentified proanthocyanidins in tested L. caerulea samples. Procyanidin dimers, trimers and up to polymers has been detected in the fruit samples by various authors [1]. Significant negative correlational interdependence was also determined between the total proanthocyanidins and average fruit weight $(R=-0.602 ; p<0.05)$. Proanthocyanidins in $L$. caerulea are also geographic origin-specific [6]. Their quantities are determined by the genotype and are negatively associated with the ripening [4]. The procyanidin dimers, trimers, and tetramers were determined in different cultivars $[7,10,11]$. Kucharska et al. study confirmed a great variation of amounts of individual and total proanthocyanidins in different cultivars [7]. The results are comparable with our tested cultivars.

The quantitative profiles were highly dependent on the cultivar. Overall, the cultivars 'Amphora', 'Indigo Gem', and 'Tundra' contained, significantly $(p<0.05)$, the greatest total amount of identified phenolic compounds $(51.4,32.6$ and $33.0 \mathrm{mg} / \mathrm{g}$, respectively), followed by 'Leningradskij Velikan' > 'Iga' > 'Wojtek' > 'Tola', the latter-only $1.7 \mathrm{mg} / \mathrm{g}$.

The identity of flavonoids and phenolic acids in extracts of $L$. caerulea fruits was additionally confirmed by mass spectrometry, which data are presented in Table 6. Obtained mass fragmentation spectra, $m / z$ proportions were identical with MS/MS data of reference compounds and literature.

Table 6. UPLC-ESI-MS/MS (negative ionization mode) data of flavonoids and phenolic acids determined in extracts of L. caerrulea fruits.

\begin{tabular}{|c|c|c|c|c|c|}
\hline Compounds & $\begin{array}{l}\text { Retention Time, } \\
\text { min }\end{array}$ & $\begin{array}{c}{[\mathrm{M}-\mathrm{H}]^{-}} \\
\quad(m / z)\end{array}$ & Other Ions $(\mathrm{m} / \mathrm{z})$ & Cone Voltage, V & $\begin{array}{c}\text { Collision Energy, } \\
\text { eV }\end{array}$ \\
\hline Rutin & 5.06 & 609 & 300 & 70 & 38 \\
\hline Isoquercitrin & 5.28 & 463 & 300 & 52 & 28 \\
\hline Quercitrin & 5.68 & 447 & 300 & 50 & 26 \\
\hline Quercetin & 6.86 & 301 & 151 & 48 & 20 \\
\hline Isorhamnetin & 7.60 & 315 & 300 & 44 & 22 \\
\hline Apigenin & 7.38 & 269 & 117 & 54 & 36 \\
\hline Luteolin-7-O-glucoside & 5.31 & 447 & 285 & 66 & 26 \\
\hline Procyanidin B1 & 3.44 & 577 & 289 & 50 & 20 \\
\hline Chlorogenic acid & 3.52 & 353 & 191 & 32 & 14 \\
\hline Caffeic acid & 3.89 & 179 & 107 & 36 & 22 \\
\hline$p$-Coumaric acid & 4.73 & 163 & 93 & 28 & 22 \\
\hline Ferulic acid & 5.18 & 193 & 134 & 32 & 18 \\
\hline Neochlorogenic acid & 2.04 & 353 & 191 & 32 & 14 \\
\hline 4-O-Caffeoylquinic acid & 3.67 & 353 & 191 & 32 & 14 \\
\hline 3,5-Dicaffeoylquinic acid & 5.62 & 515 & 353 & 50 & 25 \\
\hline 3,4-Dicaffeoylquinic acid & 5.79 & 515 & 353 & 50 & 25 \\
\hline
\end{tabular}

\subsection{Antioxidant Activity of L. of Fruits of Selected L. caerulea Cultivars}

Antioxidant activity of phenolic rich plant materials is highly correlated with the antioxidant capacity, which depends on the structural peculiarities of compounds [27,43]. In this study, the antioxidant activity was evaluated using the in vitro techniques that differ 
in mechanism of action and experimental conditions. The radical scavenging activity was evaluated using ABTS in neutral medium, while reducing activity-FRAP ( $\mathrm{pH}$ is acidic) and CuPRAC ( $\mathrm{pH}$ - close to physiological values) assays. ABTS, FRAP, and CuPRAC belong to the single electron transfer based assays [44]. CuPRAC assay due to the electronic configuration of copper complex possess faster kinetics compared to FRAP assay [26].

The greatest radical scavenging activity was determined in the samples of cultivar 'Indigo Gem' (192.34 $\pm 27.95 \mu \mathrm{mol}$ TE/g) followed by 'Leningradskij Velikan' > 'Amphora' > 'Tundra' > 'Iga' > 'Tola' > 'Wojtek' > 'Nimfa' (Table 7). Various studies determined cultivar 'Nimfa' with the lowest radical scavenging activities among 12 investigated cultivars [4,45]. The ferric reducing capacities were in a range of 107.66-707.60 $\mu \mathrm{mol} \mathrm{TE} / \mathrm{g}$ for the samples of cultivars in the following order-'Tola' $<$ 'Wojtek' $<$ 'Leningradskij Velikan' < 'Iga' < 'Nimfa' < 'Amphora' < 'Tundra' < 'Indigo Gem'. Cupric reducing capacities elucidated the highest $(p<0.05)$ antioxidant activity in cultivars 'Amphora' and 'Nimfa' (697.61 $\pm 30.86 \mu \mathrm{mol} \mathrm{TE} / \mathrm{g}$ and $670.24 \pm 42.02 \mu \mathrm{mol} \mathrm{TE} / \mathrm{g}$, respectively). Cultivar 'Tola' was distinguished with the lowest $(p<0.05)$ reducing activities. Higher antioxidant capacities have been determined for cultivars 'Indigo Gem' and 'Tundra', compared to other cultivars and certain fruits of Vaccinium and Rubus genus $[4,13,27,46]$. The three selected antioxidant evaluating methods, ABTS, FRAP, and CuPRAC, have revealed the multidirectional antioxidant capacity of L. caerulea fruit extracts and highlighted the superiority of the 'Indigo Gem' cultivar in terms of antioxidant activity. The applied antioxidant activity assays do not employ biological radicals, but, still, certain experimental setups can simulate conditions that can be met in food matrices of biological fluids, such as redox potential and $\mathrm{pH}$ [47]. Antioxidant activity mechanisms are highly interrelated with the anti-inflammatory, chemopreventive, cardioprotective, hepatoprotective, and neuroprotective activities $[1,8,19]$. The antioxidant activity of multi-phenolic compound containing plant matrices may differ due to their reaction kinetics, interactions in the sample, and peculiarities of activity enhancing structural elements [27,48].

Table 7. Antioxidant activity ( $\mu \mathrm{mol} / \mathrm{g}$, TE DW (Trolox equivalents)) and total amounts of proanthocyanidins (mg/g, DW) in cultivars of L. caerulea fruits.

\begin{tabular}{ccccc}
\hline Cultivars & $\begin{array}{c}\text { Total } \\
\text { Proanthocyanidins }\end{array}$ & ABTS & CuPRAC & FRAP \\
\hline 'Amphora' & $2.16 \pm 0.03 \mathrm{a}$ & $110.10 \pm 4.70 \mathrm{a}, \mathrm{b}, \mathrm{c}, \mathrm{d}$ & $697.61 \pm 30.86 \mathrm{a}$ & $237.27 \pm 10.91 \mathrm{c}$ \\
'Iga' & $1.06 \pm 0.01 \mathrm{~d}$ & $92.96 \pm 46.65 \mathrm{~b}, \mathrm{c}, \mathrm{d}$ & $592.51 \pm 14.80 \mathrm{a}, \mathrm{b}$ & $188.32 \pm 11.04 \mathrm{c}, \mathrm{d}$ \\
'Indigo Gem' & $1.13 \pm 0.02 \mathrm{~d}$ & $192.34 \pm 27.95 \mathrm{a}$ & $579.92 \pm 76.19 \mathrm{a}, \mathrm{b}, \mathrm{c}$ & $707.60 \pm 23.81 \mathrm{a}$ \\
'Leningradskij Velikan' & $2.13 \pm 0.01 \mathrm{a}$ & $170.54 \pm 6.66 \mathrm{a}, \mathrm{b}$ & $565.84 \pm 50.69 \mathrm{a}, \mathrm{b}, \mathrm{c}$ & $146.54 \pm 8.01 \mathrm{~d}, \mathrm{e}$ \\
'Nimfa' & $1.46 \pm 0.01 \mathrm{~b}$ & $45.54 \pm 22.57 \mathrm{~d}$ & $670.24 \pm 42.02 \mathrm{a}, \mathrm{b}$ & $208.68 \pm 17.26 \mathrm{c}, \mathrm{d}$ \\
'Tola' & $0.83 \pm 0.004 \mathrm{e}$ & $150.06 \pm 11.86 \mathrm{a}, \mathrm{b}, \mathrm{c}$ & $190.97 \pm 55.37 \mathrm{~d}$ & $107.66 \pm 1.11 \mathrm{e}$ \\
'Tundra' & $1.32 \pm 0.03 \mathrm{c}$ & $97.04 \pm 2.13 \mathrm{~b}, \mathrm{c}, \mathrm{d}$ & $515.94 \pm 4.77 \mathrm{~b}, \mathrm{c}$ & $348.28 \pm 12.50 \mathrm{~b}$ \\
'Wojtek' & $0.87 \pm 0.06 \mathrm{e}$ & $60.82 \pm 20.84 \mathrm{c}, \mathrm{d}$ & $413.11 \pm 32.98 \mathrm{c}$ & $153.32 \pm 27.72 \mathrm{~d}, \mathrm{e}$ \\
\hline
\end{tabular}

Different letters represent statistically significant differences $(p<0.05)$ between values within the same column.

Cupric reducing activities were well correlated with total proanthocyanidin content $(\mathrm{R}=0.874 ; p<0.05)$, and contents of procyanidin $\mathrm{B} 1(\mathrm{R}=0.738 ; p<0.05)$, cyanidin-3,5diglucoside $(\mathrm{R}=0.810 ; p<0.05)$, isoquercitrin $(\mathrm{R}=0.952 ; p<0.05), p$-coumaric acid $(\mathrm{R}=0.714 ; p<0.05)$, chlorogenic $(\mathrm{R}=0.881 ; p<0.05)$, caffeic $(\mathrm{R}=0.833 ; p<0.05), 3,5-$ dicaffeoylquinic acid $(\mathrm{R}=0.810 ; p<0.05)$ and ferulic acid $(\mathrm{R}=0.833 ; p<0.05)$. In our previous research, we have determined caffeoylquinic acids as fast-acting antioxidant with high capacity [48]. Esters of hydroxycinnamic acids might be more active than free phenolic acids, they stabilize radical forms more efficiently [49]. The strong antioxidant properties of proanthocyanidins can be explained by the catechol moieties in their structure and the free phenolic hydroxyl groups. The coupling of monomers with $4 \beta \rightarrow 8$ bonds provides structurally proper conditions for free radical inactivation and transition metal ion binding [50]. Zeng et al., 2020 determined the greatest antioxidant activity of procyanidin B2 
consistently in various in vitro and in vivo models [51]. Ferric reducing activities correlated with total identified anthocyanins $(\mathrm{R}=0.738 ; p<0.05)$ and individual anthocyanins with the range of coefficients $R=0.762-0.905(p<0,05)$. The results are in agreement with the study of Moyer et al., 2002, that determined correlations between total anthocyanin content and FRAP results in the samples of Vaccinium, Rubus and Ribes fruits [52]. Radical scavenging activity was correlated with cyanidin-3-glucoside $(R=0.455 ; p<0.05)$, cyanidin3-rutinoside $(\mathrm{R}=0.644 ; p<0.05)$, rutin $(\mathrm{R}=0.747 ; p<0.05)$, and procyanidin $\mathrm{B} 1(\mathrm{R}=0.545$; $p<0.05)$. Radical scavenging and reducing activities were well correlated with different groups of phenolics, indicating their versatile antioxidant potential. Correlation analysis suggested that anthocyanins and the predominant compound, cyanidin-3-glucoside, also proanthocyanidin B1,3,5-dicaffeoylquinic acid, and rutin could be proposed as markers of reducing and radical scavenging activities of $L$. caerulea fruit extracts.

\subsection{Principal Component Analysis of Fruits of Selected L. caerulea Cultivars}

The principal component (PCA) analysis was performed on the phytochemical profile components, anthocyanins, flavones, flavan-3-ols, flavonols, proanthocyanidins, and hydroxycinnamic acids. The three main derived principal components explained $78.82 \%$ of the total variance. The score plot model has shown good separation between the investigated cultivars of $L$. caerulea. The PC1 was positively correlated with the amounts of identified anthocyanins, namely cyanidin (0.927), peonidin (0.956), cyanidin-3-glucoside (0.945), peonidin-3-glucoside (0.937), cyanidin-3-galactoside (0.915), cyanidin-3-rutinoside (0.836), cyanidin-3,5-diglucoside (0.799), and constituted $43.18 \%$. The PC2 described $20.34 \%$ of the total variance and correlated positively with all the determined caffeoylquinic acids (0.675-0.918), procyanidin B1 (0.530). The PC 3 accounted for $15.30 \%$ of the total variance and was well correlated with the amounts of procyanidin B1 (0.592) and flavonoid aglycones, namely apigenin, quercetin, $(0.823,-0.958$, respectively). The arrangements of score plots of investigated cultivars are shown in Figure 2. The first segregated group included 'Wojtek', 'Iga', and 'Tola' cultivars. They all were characterized by the lowest amounts of anthocyanins, proanthocyanidins, rutin, isoquercitrin, dicaffeoylquinic acids, and lowest or average reducing and radical scavenging activities. On the other hand, this group was distinguished with the greatest amounts of luteolin-7-O-glucoside, as well as, greatest fruit weight, and the highest score of appearance. The second group included 'Indigo Gem' and 'Tundra' cultivars. They possessed the greatest reducing activities in FRAP and above the average in CuPRAC assays, as well as high amounts of cyanidin-3-glucoside. Although, they had the lowest shrub height and fruit weight. Cultivars 'Leningradskij Velikan', 'Nimfa', and 'Amphora' tended to be specific. Cultivar 'Amphora' distinguished with the highest amounts of anthocyanins and flavonol derivatives. Samples of the 'Leningradskij Velikan' cultivar were the richest in procyanidins, and flavonoid aglycones, namely apigenin, isorhamnetin. Both cultivars possessed high shrub width and the greatest density. Cultivar 'Nimfa' can be characterized by the greatest amounts of individual caffeoylquinic acids. The origin place of the cultivar determines the phytogeographical profile in a qualitative and quantitative manner. Numerous studies support information, that Russian cultivars contain higher amounts of phytochemicals $[3,4,17]$. In our study, the PCA analysis on phenolics clearly defined the cultivars into groups in the relation to their origin. The lowest $(p<0.05)$ total amounts of all groups of identified compounds, as well as, the lowest antioxidant capacities were determined for the Polish cultivars, namely 'Wojtek', 'Iga' and 'Tola'. Genotype characterization resulted in the highest appearance and fruit weight scores. The Canadian cultivars 'Indigo Gem' and 'Tundra' were distinguished with the highest ferric reducing antioxidant power and low fruit weight. The Russian cultivars had the greatest anthocyanin contents and were specific in dominant phenolics of different chemical groups. 


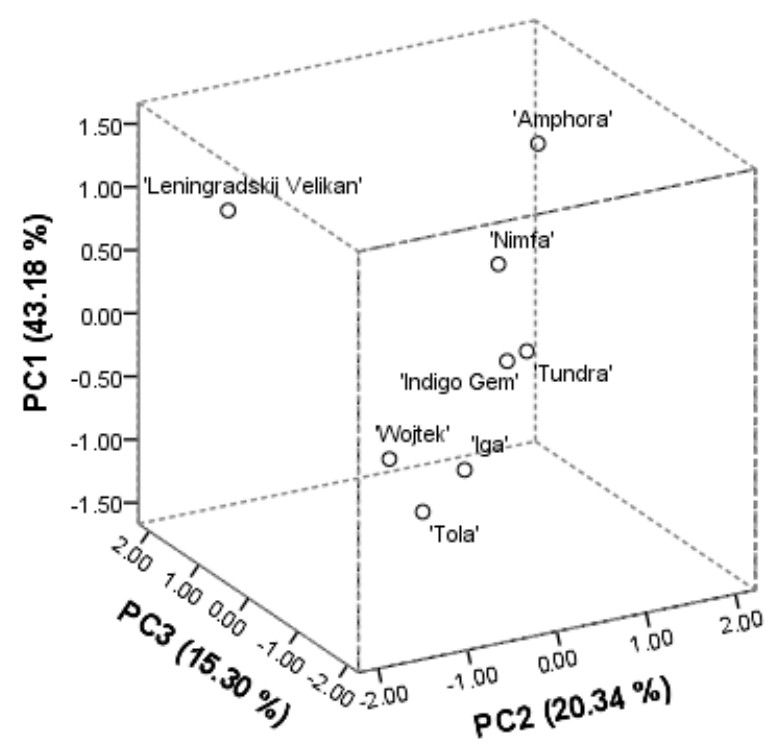

Figure 2. PCA score plots for the three principal components based on the phytochemical composition of L. caerulea fruits.

\section{Conclusions}

Lonicera caerulea fruit are attractive as polyphenolic containing materials with multidirectional antioxidant properties. The phenolic profiles are genotype variable and origin dependent. The key quantitative analytical markers of phytochemical profiles are cyanidin3-glucoside, rutin, chlorogenic and 3,5-dicaffeoylquinic acid. These markers are suitable for the standardization of $L$. caerulea fruit preparations to control the quality and to ensure consistent, reproducible biological activity. The structural diversity of phenolic compounds in multicomponent plant matrices results in a very high potency antioxidant activity that was detected in all model systems. Cultivars 'Amphora', 'Indigo Gem', and 'Tundra' contained the greatest total amounts of identified phenolic compounds. The Russian origin cultivars, namely, 'Amphora', 'Leningradskij Velikan' and 'Nimfa' were specific in dominant phenolics, anthocyanins, proanthocyanidins, and caffeoylquinic acids, respectively. Tested cultivars showed significant differences in plant height, width, and density. All selected L. caerulea plants are suitable for growing in Lithuania, though cultivar characterization revealed the superiority of 'Wojtek' and 'Tundra' compared to other cultivars, although 'Wojtek' had low phenolic content and antioxidant activity and 'Tundra' got lower sensory evaluation scores. Coupling the results of cultivar and phytochemical characterization, cultivar 'Tundra' could be suitable for commercial plantations. The obtained results could be used in further research evaluating chemotaxonomical significance, phytogeographical profiles, and in biological effect studies.

Author Contributions: Conceptualization, L.R. and D.K.; methodology, G.V., M.L., J.V.; validation, G.V.; formal analysis, L.R., M.L., D.K.; investigation, M.L., G.V., V.Ž.; resources, D.K., J.V., P.V.; data curation, L.R.; writing — original draft preparation, L.R., D.K.; writing—review and editing, L.R., D.K., G.V.; visualization, L.R.; supervision, L.R.; project administration, P.V. All authors have read and agreed to the published version of the manuscript.

Funding: This research received no external funding.

Institutional Review Board Statement: Not applicable.

Informed Consent Statement: Not applicable.

Data Availability Statement: All datasets generated for this study are included in the article.

Acknowledgments: This study is partly attributed to the EUREKA Network Project E!13496 "OHMDRINKS" (No. 01.2.2-MITA-K-702-08-003). 
Conflicts of Interest: The authors declare no conflict of interest.

\section{References}

1. Sharma, A.; Lee, H.-J. Lonicera caerulea: An updated account of its phytoconstituents and health-promoting activities. Trends Food Sci. Technol. 2021, 107, 130-149. [CrossRef]

2. Auzanneau, N.; Weber, P.; Kosińska-Cagnazzo, A.; Andlauer, W. Bioactive compounds and antioxidant capacity of Lonicera caerulea berries: Comparison of seven cultivars over three harvesting years. J. Food Compos. Anal. 2018, 66, 81-89. [CrossRef]

3. Caprioli, G.; Iannarelli, R.; Innocenti, M.; Bellumori, M.; Fiorini, D.; Sagratini, G.; Vittori, S.; Buccioni, M.; Santinelli, C.; Bramucci, M.; et al. Blue honeysuckle fruit (Lonicera caerulea L.) from eastern Russia: Phenolic composition, nutritional value and biological activities of its polar extracts. Food Funct. 2016, 7, 1892-1903. [CrossRef] [PubMed]

4. Gołba, M.; Sokół-Łetowska, A.; Kucharska, A.Z. Health properties and composition of honeysuckle berry Lonicera caerulea L. An update on recent studies. Molecules 2020, 25, 759. [CrossRef] [PubMed]

5. Kottek, M.; Grieser, J.; Beck, C.; Rudolf, B.; Rubel, F. World Map of the Köppen-Geiger climate classification updated. Meteorol. Z. 2006, 15, 259-263. [CrossRef]

6. Jurikova, T.; Rop, O.; Mlcek, J.; Sochor, J.; Balla, S.; Szekeres, L.; Hegedusova, A.; Hubalek, J.; Adam, V.; Kizek, R. Phenolic profile of edible honeysuckle berries (genus Lonicera) and their biological effects. Molecules 2012, 17, 61-79. [CrossRef]

7. Kucharska, A.Z.; Sokól-Lȩtowska, A.; Oszmiánski, J.; Piórecki, N.; Fecka, I. Iridoids, phenolic compounds and antioxidant activity of edible honeysuckle berries (Lonicera caerulea var. kamtschatica Sevast.). Molecules 2017, 22, 405. [CrossRef]

8. Rupasinghe, H.P.V.; Arumuggam, N.; Amararathna, M.; De Silva, A.B.K.H. The potential health benefits of haskap (Lonicera caerulea L.): Role of cyanidin-3-O-glucoside. J. Funct. Foods 2018, 44, 24-39. [CrossRef]

9. Becker, R.; Szakiel, A. Phytochemical characteristics and potential therapeutic properties of blue honeysuckle Lonicera caerulea L. (Caprifoliaceae). J. Herb. Med. 2019, 16, 100237. [CrossRef]

10. Oszmiański, J.; Wojdyło, A.; Lachowicz, S. Effect of dried powder preparation process on polyphenolic content and antioxidant activity of blue honeysuckle berries (Lonicera caerulea L. var. kamtschatica). LWT Food Sci. Technol. 2016, 67, 214-222. [CrossRef]

11. Senica, M.; Stampar, F.; Mikulic-Petkovsek, M. Blue honeysuckle (Lonicera cearulea L. subs. edulis) berry; A rich source of some nutrients and their differences among four different cultivars. Sci. Hortic. 2018, 238, 215-221. [CrossRef]

12. Liu, W.; Yin, D.; Li, N.; Hou, X.; Wang, D.; Li, D.; Liu, J. Influence of Environmental Factors on the Active Substance Production and Antioxidant Activity in Potentilla fruticosa L. and Its Quality Assessment. Sci. Rep. 2016, 6, 1-18. [CrossRef]

13. Khattab, R.; Brooks, M.S.L.; Ghanem, A. Phenolic analyses of haskap berries (Lonicera caerulea L.): Spectrophotometry versus high performance liquid chromatography. Int. J. Food Prop. 2015, 19, 1708-1725. [CrossRef]

14. Myjavcová, R.; Marhol, P.; Křen, V.; Šimánek, V.; Ulrichová, J.; Palíková, I.; Papoušková, B.; Lemr, K.; Bednář, P. Analysis of anthocyanin pigments in Lonicera (Caerulea) extracts using chromatographic fractionation followed by microcolumn liquid chromatography-mass spectrometry. J. Chromatogr. A 2010, 1217, 7932-7941. [CrossRef] [PubMed]

15. Wang, Y.; Zhu, J.; Meng, X.; Liu, S.; Mu, J.; Ning, C. Comparison of polyphenol, anthocyanin and antioxidant capacity in four varieties of Lonicera caerulea berry extracts. Food Chem. 2016, 197, 522-529. [CrossRef] [PubMed]

16. Molina, A.K.; Vega, E.N.; Pereira, C.; Dias, M.I.; Heleno, S.A.; Rodrigues, P.; Fernandes, I.P.; Barreiro, M.F.; Kostic, M.; Sokovic, M.; et al. Promising Antioxidant and Antimicrobial Food Colourants from Lonicera caerulea L. var. Kamtschatica. Antioxidants 2019, 8, 394. [CrossRef] [PubMed]

17. Gawroński, J.; Żebrowska, J.; Pabich, M.; Jackowska, I.; Kowalczyk, K.; Dyduch-Siemińska, M. Phytochemical Characterization of Blue Honeysuckle in Relation to the Genotypic Diversity of Lonicera sp. Appl. Sci. 2020, 10, 6545. [CrossRef]

18. Naugžemys, D.; Žilinskaite, S.; Kleizaite, V.; Skridaila, A.; Žvingila, D. Assessment of genetic variation among elite and wild germplasm of blue honeysuckle (Lonicera caerulea L.). Balt. For. 2011, 17, 8-16.

19. Zdařilová, A.; Svobodová, A.R.; Chytilová, K.; Šimánek, V.; Ulrichová, J. Polyphenolic fraction of Lonicera caerulea L. fruits reduces oxidative stress and inflammatory markers induced by lipopolysaccharide in gingival fibroblasts. Food Chem. Toxicol. 2010, 48, 1555-1561. [CrossRef]

20. Blažek, J. Protection of genetic resources of pomolical plants and selection of genitors with traits valuable for sustainable fruit production. Response to disease in new apple cultivars froms the Czech Republic. J. Fruit Ornam. Plant Res. 2004, 12, 241-250.

21. Ratti, C. Freeze drying for food powder production. In Handbook of Food Powders; Bhandari, B., Bansal, N., Zhang, M., Schuck, P., Eds.; Woodhead Publishing Limited: Oxford, UK, 2013; pp. 57-84.

22. Liu, J.; Yong, H.; Liu, Y.; Qin, Y.; Kan, J.; Liu, J. Preparation and characterization of active and intelligent films based on fish gelatin and haskap berries (Lonicera caerulea L.) extract. Food Packag. Shelf Life 2019, 22, 100417. [CrossRef]

23. Heil, M.; Baumann, B.; Andary, C.; Linsenmair, K.E.; McKey, D. Extraction and quantification of "condensed tannins" as a measure of plant anti-herbivore defence? Revisiting an old problem. Naturwissenschaften 2002, 89, 519-524. [CrossRef] [PubMed]

24. Re, R.; Pellegrini, N.; Proteggente, A.; Pannala, A.; Yang, M.; Rice-Evans, C. Antioxidant activity applying an improved ABTS radical cation decolorization assay. Free Radic. Biol. Med. 1999, 26, 1231-1237. [CrossRef]

25. Benzie, I.F.F.; Strain, J.J. The ferric reducing ability of plasma (FRAP) as a measure of "antioxidant power": The FRAP assay. Anal. Biochem. 1996, 239, 70-76. [CrossRef] [PubMed] 
26. Apak, R.; Güçlü, K.; Demirata, B.; Özyürek, M.; Çelik, S.E.; Bektaşoğlu, B.; Berker, K.I.; Özyurt, D. Comparative evaluation of various total antioxidant capacity assays applied to phenolic compounds with the CUPRAC assay. Molecules 2007, 12, 1496-1547. [CrossRef] [PubMed]

27. Raudone, L.; Vilkickyte, G.; Pitkauskaite, L.; Raudonis, R.; Vainoriene, R.; Motiekaityte, V. Antioxidant Activities of Vaccinium vitis-idaea L. Leaves within cultivars and their phenolic compounds. Molecules 2019, 24, 844. [CrossRef]

28. Liaudanskas, M.; Viškelis, P.; Jakštas, V.; Raudonis, R.; Kviklys, D.; Milašius, A.; Janulis, V. Application of an optimized HPLC method for the detection of various phenolic compounds in apples from Lithuanian cultivars. J. Chem. 2014, 2014. [CrossRef]

29. González-Burgos, E.; Liaudanskas, M.; Viškelis, J.; Žvikas, V.; Janulis, V.; Gómez-Serranillos, M.P. Antioxidant activity, neuroprotective properties and bioactive constituents analysis of varying polarity extracts from Eucalyptus globulus leaves. J. Food Drug Anal. 2018, 26, 1293-1302. [CrossRef]

30. Vilkickyte, G.; Motiekaityte, V.; Vainoriene, R.; Liaudanskas, M.; Raudone, L. Development, validation, and application of UPLC-PDA method for anthocyanins profiling in Vaccinium L. berries. J. Berry Res. 2021. [CrossRef]

31. Ochmian, I.; Krawkowski, J.; Skupiec, K. Field performance, fruit chemical composition and firmness under cold storage and simulated "shelf-life" conditions of three blue honeysuckle cultigens (Lonicera caerulea). J. Fruit Ornam. Plant Res. 2008, 16, 83-91.

32. Hummer, K.E. A new berry crop for North America. J. Am. Pomol. Soc. 2006, 60, 3-8.

33. Thompson, M.M.; Barney, D.L. Evaluation and breeding of haskap in North America. J. Am. Pomol. Soc. 2007, 61, 25-33.

34. Malodobry, M.; Bieniasz, M.; Dziedzic, E. Evaluation of the field and some components in the fruit of blue honeysuckle (Lonicera caerulea var. edulis Turcz. Freyn.). Folia Hort. 2010, 22, 45-50. [CrossRef]

35. Gawronski, J.; Hortynski, J.; Kaczmarska, E.; Dyduch-Sieminska, M.; Marecki, W.; Witorozec, A. Evaluation of phenotypic and genotypic diversity of some polish and russian blue honeysuckle (Lonicera caerulea L.) cultivars and clones. Acta Sci. Pol. Hortorum Cultus 2014, 13, 157-169.

36. Szot, I.; Lipa, T. Estimating the fruit quality after application the pruning of blue honeysuckle bushes. Mod. Phytomorphol. 2013, 4, 51-54. [CrossRef]

37. Wojdyło, A.; Jáuregui, P.N.N.; Carbonell-Barrachina, Á.A.; Oszmiański, J.; Golis, T. Variability of phytochemical properties and content of bioactive compounds in lonicera caerulea L. var. kamtschatica Berries. J. Agric. Food Chem. 2013, 61, 12072-12084. [CrossRef] [PubMed]

38. Wang, Y.; Li, B.; Lin, Y.; Ma, Y.; Zhang, Q.; Meng, X. Effects of Lonicera caerulea berry extract on lipopolysaccharide-induced toxicity in rat liver cells: Antioxidant, anti-inflammatory, and anti-apoptotic activities. J. Funct. Foods 2017, 33, 217-226. [CrossRef]

39. Zhou, L.; Wang, H.; Yi, J.; Yang, B.; Li, M.; He, D.; Yang, W.; Zhang, Y.; Ni, H. Anti-tumor properties of anthocyanins from Lonicera caerulea 'Beilei' fruit on human hepatocellular carcinoma: In vitro and in vivo study. Biomed. Pharm. 2018, 104, 520-529. [CrossRef]

40. Mikulic-Petkovsek, M.; Schmitzer, V.; Slatnar, A.; Stampar, F.; Veberic, R. Composition of Sugars, Organic Acids, and Total Phenolics in 25 Wild or Cultivated Berry Species. J. Food Sci. 2012, 77, C1064-C1070. [CrossRef]

41. Liu, S.; Yu, J.; Guo, S.; Fang, H.; Chang, X. Inhibition of pancreatic $\alpha$-amylase by Lonicera caerulea berry polyphenols in vitro and their potential as hyperglycemic agents. LWT 2020, 126, 109288. [CrossRef]

42. Gonzalez-Abuin, N.; Pinent, M.; Casanova-Marti, A.; Arola, L.; Blay, M.; Ardevol, A. Procyanidins and Their Healthy Protective Effects Against Type 2 Diabetes. Curr. Med. Chem. 2014, 22, 39-50. [CrossRef] [PubMed]

43. Raudone, L.; Raudonis, R.; Liaudanskas, M.; Viskelis, J.; Pukalskas, A.; Janulis, V. Phenolic Profiles and Contribution of Individual Compounds to Antioxidant Activity of Apple Powders. J. Food Sci. 2016, 81. [CrossRef]

44. Sadeer, N.B.; Montesano, D.; Albrizio, S.; Zengin, G.; Mahomoodally, M.F. The versatility of antioxidant assays in food science and safety-Chemistry, applications, strengths, and limitations. Antioxidants 2020, 9, 709. [CrossRef]

45. Rop, O.; Řezníček, V.; Mlček, J.; Juríková, T.; Balík, J.; Sochor, J.; Kramářová, D. Antioxidant and radical oxygen species scavenging activities of 12 cultivars of blue honeysuckle fruit. Hort. Sci. 2011, 38, 63-70. [CrossRef]

46. Vasantha Rupasinghe, H.P.; Yu, L.J.; Bhullar, K.S.; Bors, B. Short Communication: Haskap (Lonicera caerulea): A new berry crop with high antioxidant capacity. Can. J. Plant Sci. 2012, 92, 1311-1317. [CrossRef]

47. Apak, R.; Mustafa, O.; Guclu, K.; Çapanoglu, E. Antioxidant Activity/Capacity Measurement. 1. Classification, Physicochemical Principles, Mechanisms, and Electron Transfer (ET)-Based Assays. J. Agric. Food Chem. 2016, 64, 997-1027. [CrossRef] [PubMed]

48. Marksa, M.; Zymone, K.; Ivanauskas, L.; Radušienè, J.; Pukalskas, A.; Raudone, L. Antioxidant profiles of leaves and inflorescences of native, invasive and hybrid Solidago species. Ind. Crop. Prod. 2020, 145, 112123. [CrossRef]

49. Chen, Y.; Xiao, H.; Zheng, J.; Liang, G. Structure-thermodynamics-antioxidant activity relationships of selected natural phenolic acids and derivatives: An experimental and theoretical evaluation. PLoS ONE 2015, 10, e0121276. [CrossRef] [PubMed]

50. Spranger, I.; Sun, B.; Mateus, A.M.; de Freitas, V.; Ricardo-da-Silva, J.M. Chemical characterization and antioxidant activities of oligomeric and polymeric procyanidin fractions from grape seeds. Food Chem. 2008, 108, 519-532. [CrossRef]

51. Zeng, Y.; Song, J.; Zhang, M.; Wang, H.; Zhang, Y.; Suo, H. Comparison of In Vitro and In Vivo Antioxidant Activities of Six Flavonoids with Similar Structures. Antioxidants 2020, 9, 732. [CrossRef]

52. Moyer, R.A.; Hummer, K.E.; Finn, C.E.; Frei, B.; Wrolstad, R.E. Anthocyanins, phenolics, and antioxidant capacity in diverse small fruits: Vaccinium, Rubus, and Ribes. J. Agric. Food Chem. 2002, 50, 519-525. [CrossRef] [PubMed] 